\title{
Education and research in medical optronics in France
}

Jacques Demongeot, M. Fleute, T. Herve, Stephane Lavallee

Jacques Demongeot, M. Fleute, T. Herve, Stephane Lavallee, "Education and research in medical optronics in France," Proc. SPIE 3831, Sixth International Conference on Education and Training in Optics and Photonics, (16 June 2000); doi: 10.1117/12.388709

SPIE Event: Education and Training in Optics and Photonics (ETOP'99), 1999, Cancun, Mexico 


\title{
Education \& Research in Medical Optronics in France
}

\author{
J. Demongeot* ${ }^{*}$, M. Fleute*, T. Hervé* \& S. Lavallée* \\ TIMC-IMAG* \& IUF市 \\ Faculty of Medicine \\ University J. Fourier of Grenoble \\ 38700 La Tronche France \\ Summary
}

First we present here the main post-graduate courses proposed in France both for physicians and engineers in medical optronics. After we explain which medical domains are concerned by this teaching, essentially computer assisted surgery, telemedicine and functional exploration. Then we show the main research axes in these fields, in which new jobs have to be invented and new educational approaches have to be prepared in order to satisfy the demand coming both from hospitals (mainly referent hospitals) and from industry (essentially medical imaging and instrumentation companies). Finally we will conclude that medical optronics is an important step in an entire chain of acquisition and processing of medical data, capable to create the medical knowledge a surgeon or a physician needs for diagnosis or therapy purposes. Optimizing the teaching of medical optronics needs a complete integration from acquiring to modelling the medical reality. This tendancy to give a holistic education in medical imaging and instrumentation is called "Model driven Acquisition" learning.

\section{Introduction}

Since about 12 years, France has invested a lot in medical optics and photonics, essentially on the optronic side (i.e. in the field resulting from mixing optics and electronics). In this paper, we will present successively the major post-graduate training courses teached at faculties of medicine or at engineering institutions levels in medical optronics. After, we will give some information about the research axes and clinical topics in which we presently need new actors exerting new jobs in medical optronic acquisition and processing: computer assisted surgery, telemedicine and functional exploration. Finally, we will conclude by considering the acquisition process as not isolated, but taking part of a whole programme of observing and modelling the medical reality, serving for example as a template for generating an augmented reality a physician and a surgeon can exploit in order to improve their classical diagnostic or therapic procedures.

\section{French post-graduate courses in medical optronics}

Different institutions of both medical and engineering worlds bring a basic education in classical optics and in electronics for medical applications during the master $(1$ year) and the $\mathrm{PhD}(3$ years) degrees. The main locations where this teaching is provided are the following:

Paris (Ile de France Region)

In Paris V, Paris VI and ParisVII, there is $2 \mathrm{PhD}$ degree sites, one in Medical Informatics and the second in Bio-Mathematics, involved in optronic acquisition and processing, each $\mathrm{PhD}$ education site being able to teach about 20 new students each year. In Paris suburbs, the "Ecole Centrale des Arts \& Manufactures" of Chatenay-Malabry has a master degree and a $\mathrm{PhD}$ degree in Bio-modelling (about 10 new students each year) and the "Technologic University" of Compiegne (UTC) has master (about 60 new students each year) and $\mathrm{PhD}$ degrees in Bio-engineering and Medical Imaging (about 10 new students each year)

Lyons-Grenoble (Rhone-Alpes Region)

In Lyons and Grenoble, $2 \mathrm{PhD}$ degrees (managed by 2 "Ecoles Doctorales d'Ingenierie pour la Sante", i.e. 2 Bio-engineering $\mathrm{PhD}$ formations) include inside their courses an education in medical optronics: the 2 corresponding titles are "Bio-medical Engineering" and "Models and Instruments in Medicine \& Biology", each "Ecole Doctorale" being able to welcome about 30 new students each year. A new "doctor-engineer" curriculum has been recently proposed at Grenoble, on the topics "Computer Assisted Surgery", "Telemedicine" and "Management of Medical Data Bases" 
Besançon (Franche Comte Region)

A new "doctor-engineer" curriculum has been recently proposed at Besançon on the topic "Medical Instrumentation and Medical Informatics", based both on a deep formation in classical optics and optronics and in data base management systems (with a special devotion to microscopic imaging and to micro- nanotechnologies), with about 20 new students each year.

The main topics teached in the courses mentionned above are : classical optics, elements of Fourier-LaplaceGabor-Radon-Meyer transforms, basic electronics, basic image and signal processing methods (3D reconstruction, thin plate Duchon's spline approximation, ray tracing method of visualization, optical flow method of velocity vector field extraction in 4D imaging, 3D registration, signal contrasting \& filtering, neural networks approach for enhancement and classification,...), introduction to robotics, introduction to sensor hardware, data fusion techniques.

Two 2-weeks European summer schools (Berder in Brittany for imaging \& instrumentation and St Flour in Auvergne for bio-modelling) are completing the French education \& research network described above.

\section{Computer assisted surgery}

The role of optronics in computer assisted surgery (CAS) is multiple :

- to localize the patient surface structures in the operation theater (OT) (by using passive or active infra-red sensors)

- to match the 3D referential corresponding to the deep anatomic structures (acquired by an $\mathrm{X}$ detector in the OT) with the 3D referential of the patient surface structures in the OT (Fig. 1 \& 2)

- to match the deep and surface 3D referentials of the patient in the OT with the pre-operative (CT-scanner, anatomic or functional NMR, 3D US, PET or SPECT, MEG, ..., image devices) referentials

- to guide (e.g. with a laser beam) the surgeon tools.

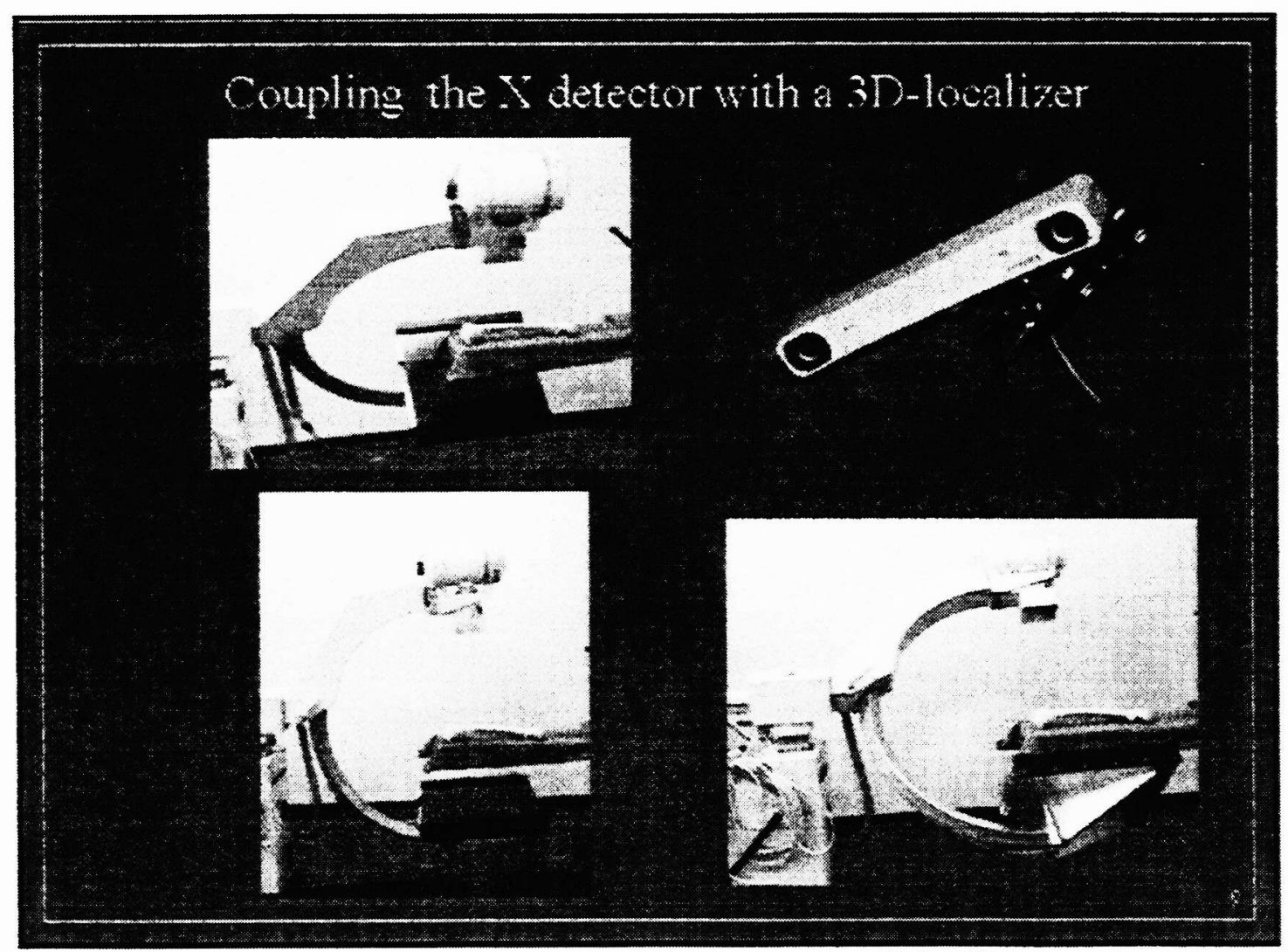

Figure 1 : coupling the $\mathrm{X}$ detector with a 3D-localizer 


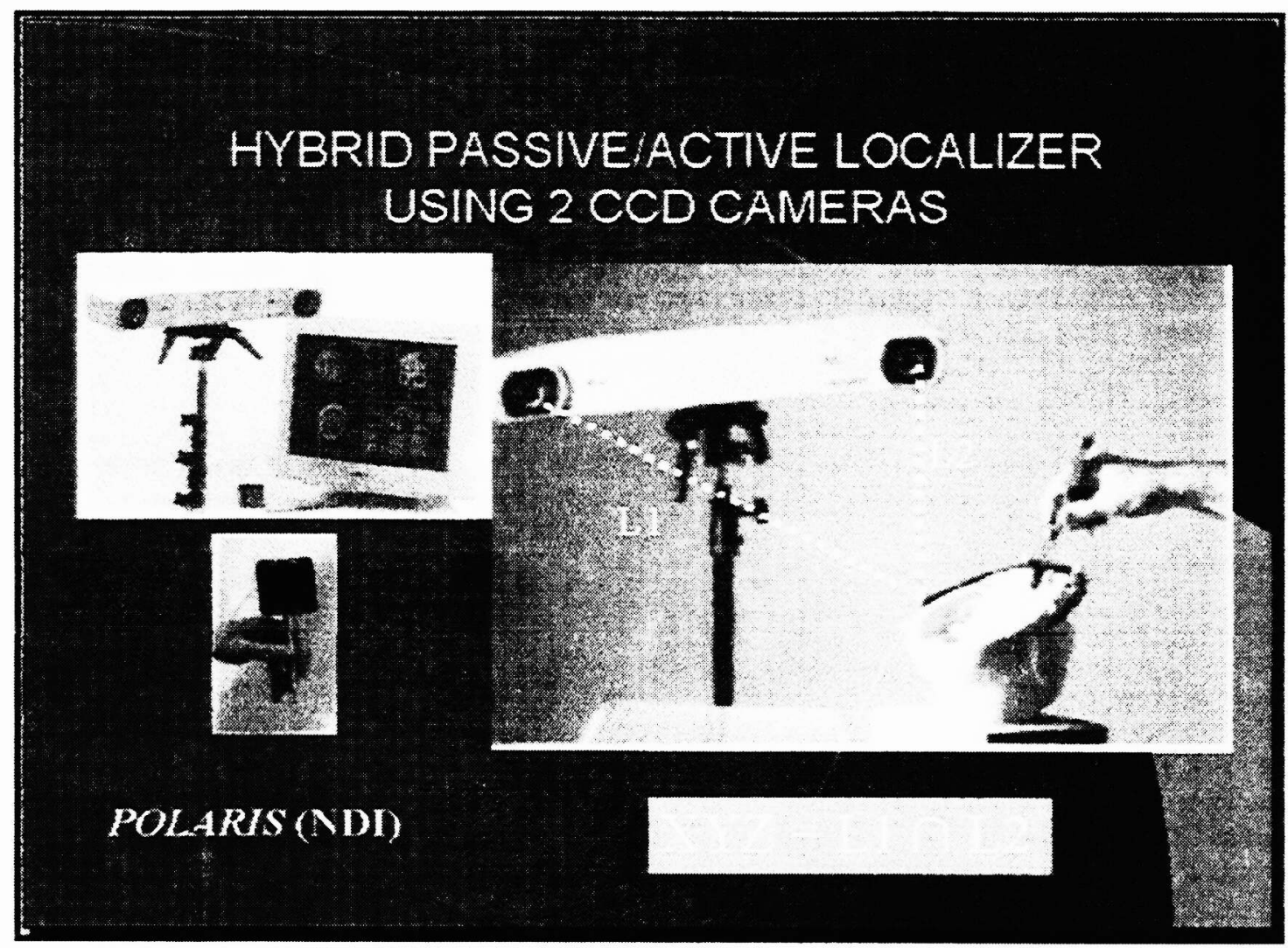

Figure 2 : hvbrid passive/active localizer using $2 \mathrm{CCD}$ cameras

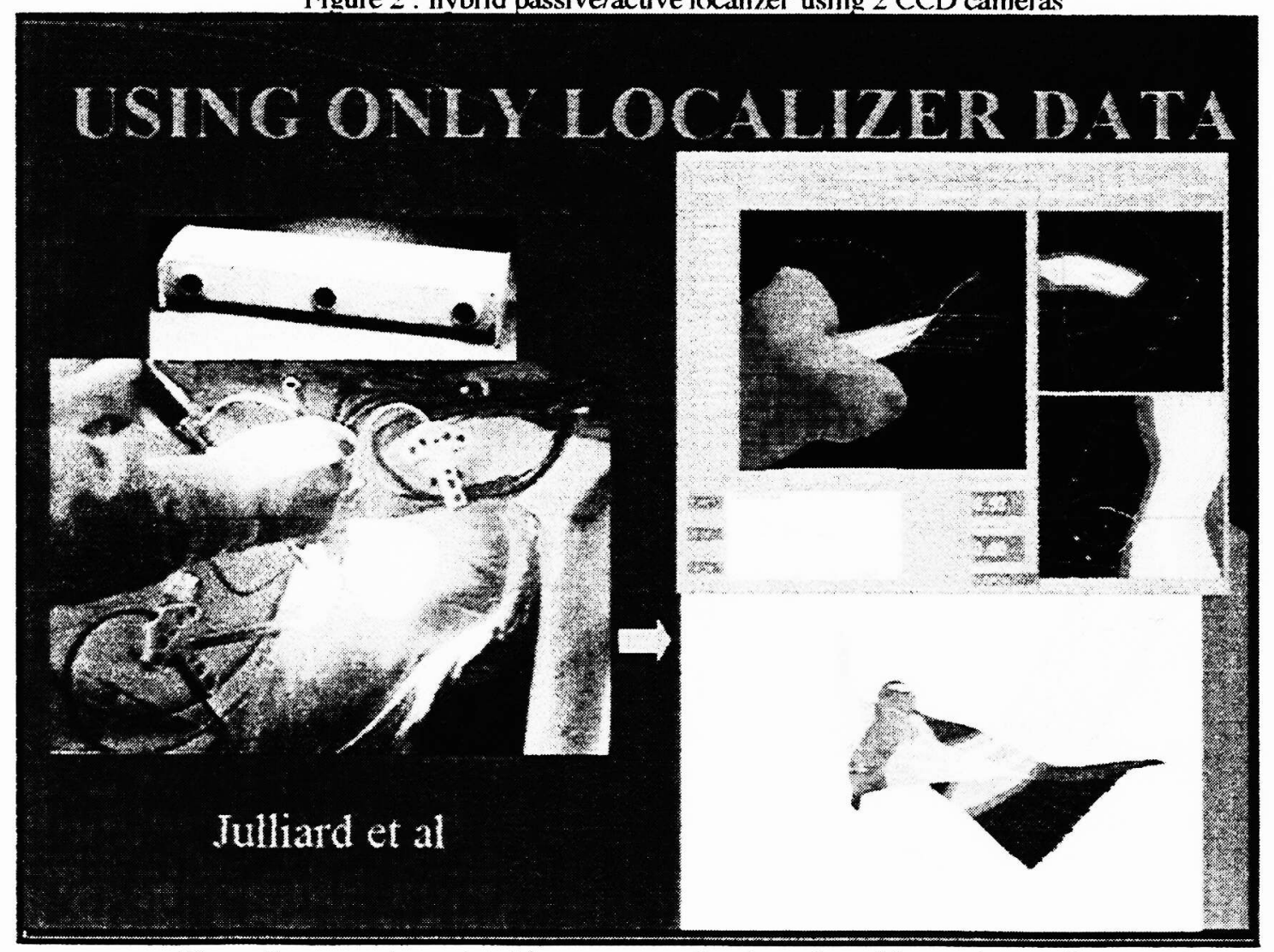

Figure 3 : computer assisted knee surgery (implantation of internal cross ligaments) 


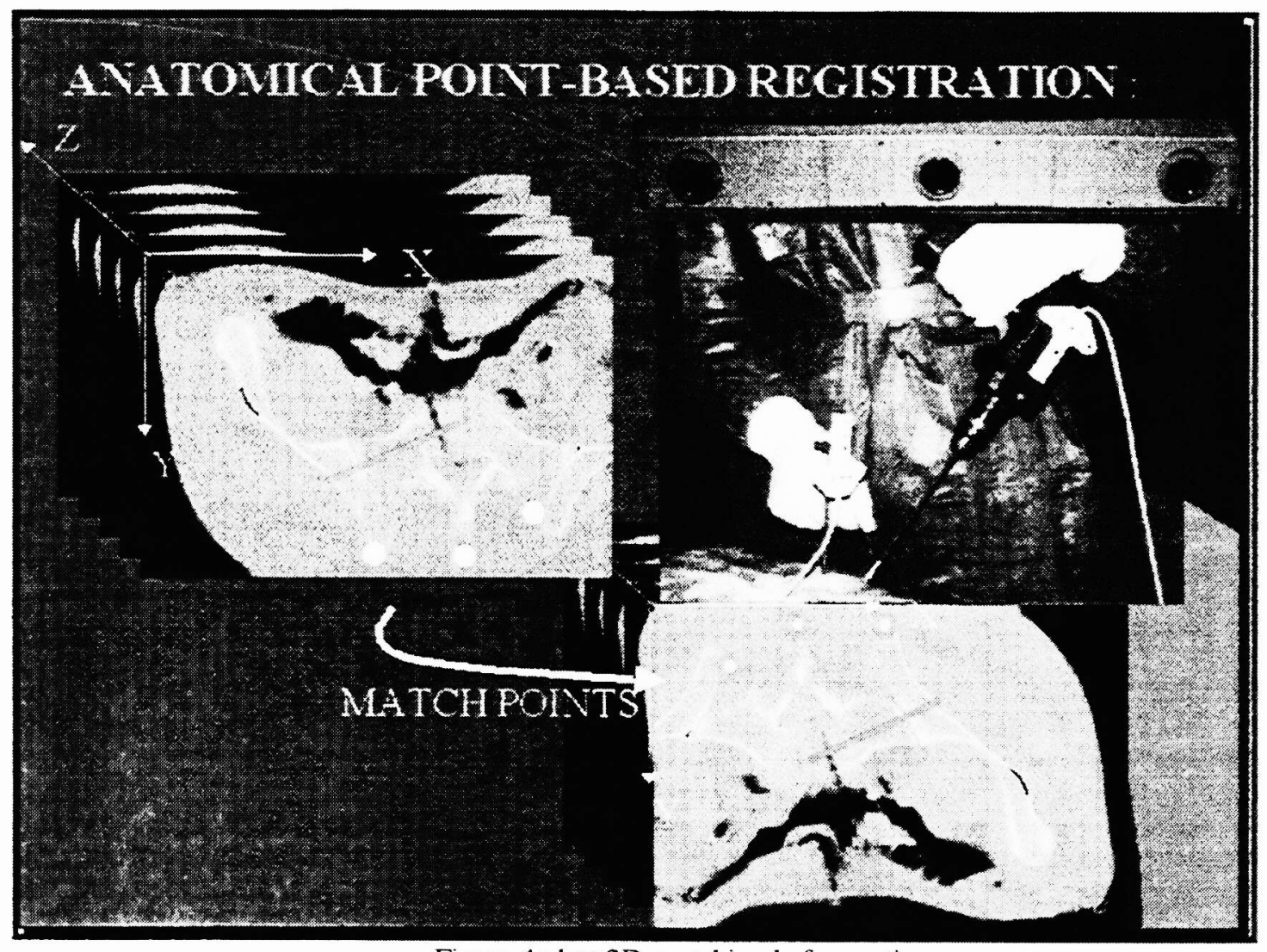

Figure 4 : last 3D-matching before action

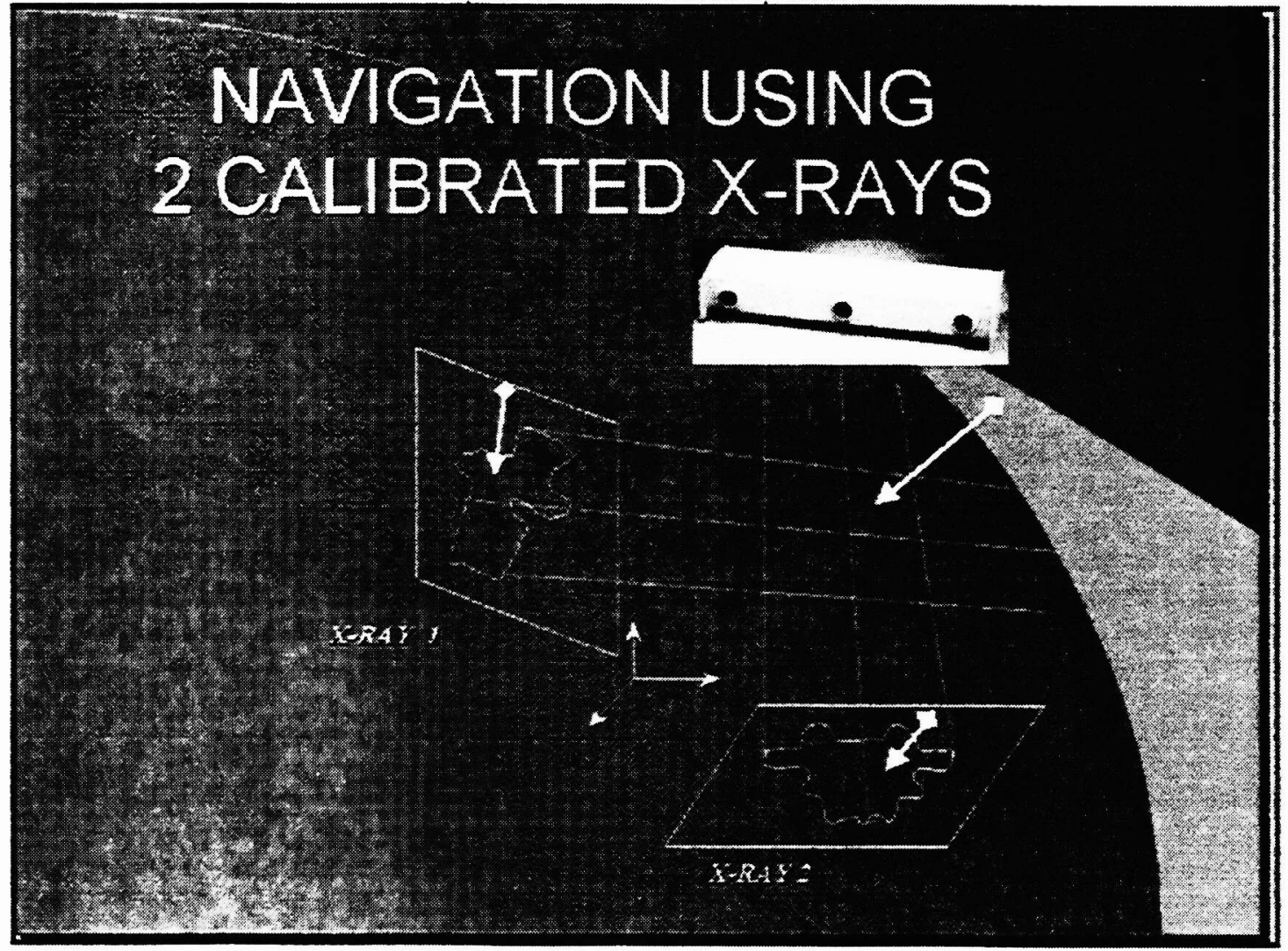

Figure 5 : navigation using 2 calibrated $\mathrm{X}$-rays 
These techniques can be applied to many domains of CAS : knee surgery (implanting internal cross ligaments, Fig. 3), neuro-surgery (putting electrodes in deep structures involved in Parkinson's disease), back surgery (putting screws in vertebras) and ant \& maxillo-facial surgery (putting material in the mandible, Fig. 4).

In a near future the own surgeon hand provided by a specific surgical tool (bistoury, biopsy puncture needle, Kocher pinch,...) will be guided at each time in a cone of admissible trajectories : if the surgeon wants to force the CAS system, he can, but a auditory, visual or lingual signal can recall him that he is escaping out the pre-chosen trajectory set of cones going from the skin opening to the final surgical target. To achieve such a hand real-time control, the successive $3 \mathrm{D}$ locations of the tool have to be precisely acquired by using an passive or active optical or electro-magnetic marker located on the top and on the bottom of the tool.

\section{Optronic sensors in telemedicine and functional exploration}

Both telemedicine and functional exploration represent elective fields for optronic sensing. Numerous experiments are documented, among them we can mention two French ones.

\subsection{Watching elderly people at home}

In order to perform a non-invasive watch of elderly people at home, different solutions have been recently proposed in France :

- use of an smart mattress with 1000 pressure sensors acquiring each $0.4 \mathrm{~s}$ an "image" of the patient on his bed, allowing the detection of pathologic exits and of potential skin breaches due to friction. This pressure signal is correlated with an infra-red one (cut of infra-red beams around the bed) and with a video-camera recording with a remote control (for zooming and following up the patient by the nurses of the "Hospital at Home" service located at the referent hospital). It is interesting to notice that for confidentiality reasons, only an automatic alarm triggering resulting from a multi-sensor data fusion will be possible in the future (in particular, the direct video-watching elderly people at home will be suppressed in France, because of its prohibition by the French Commission "Informatics and Freedom")

- use of an smart network of infrared sensors dispatched in the patient flat, each watching an area of about $1 \mathrm{~m}^{2}$; this overlook being in general completed by a pressure and/or video acquisition (the same confidentiality problems occurring than for the bed watch, leading to the same constraint of integrating multi-sensor data and of automatic alarm triggering).

\subsection{Performing respiratory functional exploration}

In situ quantification of a marker concentration in pulmonary alveolar volumes allows the monitoring of the capillaro-alveolar permeability.

\subsubsection{Medical application}

Any inflamation of the capillaro-alveolar membrane is a sign of an increase of its permeability which leads to pulmonary oedema. It can be a symptom of adult respiratory distress syndrome or asthma which are major concerns in public health.

In classical clinical exploration, a fluorescent marker (dextran-like) is injected in the patient's blood. The marker diffuses towards pulmonary alveols and remains in the Epithelium Lining Fluid which covers the bronchial walls. A broncho-alveolar washing is then performed by the physician and at regular periods some fluid is extracted for later analysis in a distant laboratory. The typical analysis consists in a fluorescence spectrometry wich enables to measure the concentration of dextran contained in the broncho-alveolar fluid. The project aims to develop a device that would allow direct in situ recording of the dextran concentration. Such a device will provide in a short term the kinetics of the marker diffusion from blood to alveols.

\subsubsection{Microsystem based on silicon micromachining and bioreceptors membrane}

The basic structure of the Mach-Zehnder microinterferometer has been developped by C. Gorecki et collaborators at LIMMS (joint French/Japanese Laboratory for Integrated Microelectro-Mechanical Systems) [Gorecki et al. 97]. A sensitive window is designed by adding a superstrate layer on one arm of the 
interferometer. This superstrate layer interacts with the evanescent part of the wave in such a way that it modifies the effective refractive index of this part of the guide.

Any variation of the refractive index in one arm of the interferometer induces interferences such that :

$$
\frac{I(\Delta \Phi)}{I_{0}}=\frac{1}{2}\left[1+\cos \left(\frac{2 \pi}{\lambda} L \Delta n_{e f f}\right)\right]
$$

with I the intensity, $\lambda$ the wave length. $\mathrm{L}$ represents the length of the sensitive window. A sensitivity of $10^{-4}$ to $10^{-6}$ is targeted for detecting changes in the effective refractive index $\Phi$.

In order to detect the molecules of dextran that are used in this application a biomolecular film is deposited onto the sensitive window as shown is the Figure 6. When dextran is fixed by the receptors the effective refractiveness of the sensitive window is changed thus generating interferences [Herve et al. 98].

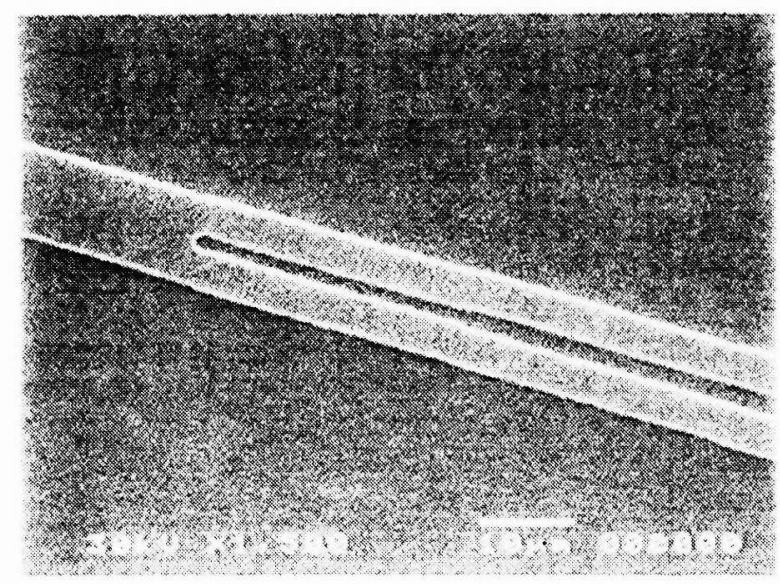

Figure $6:$ Y Junction of the microinterferometer wave guide obtained by

\section{Sensitive area}

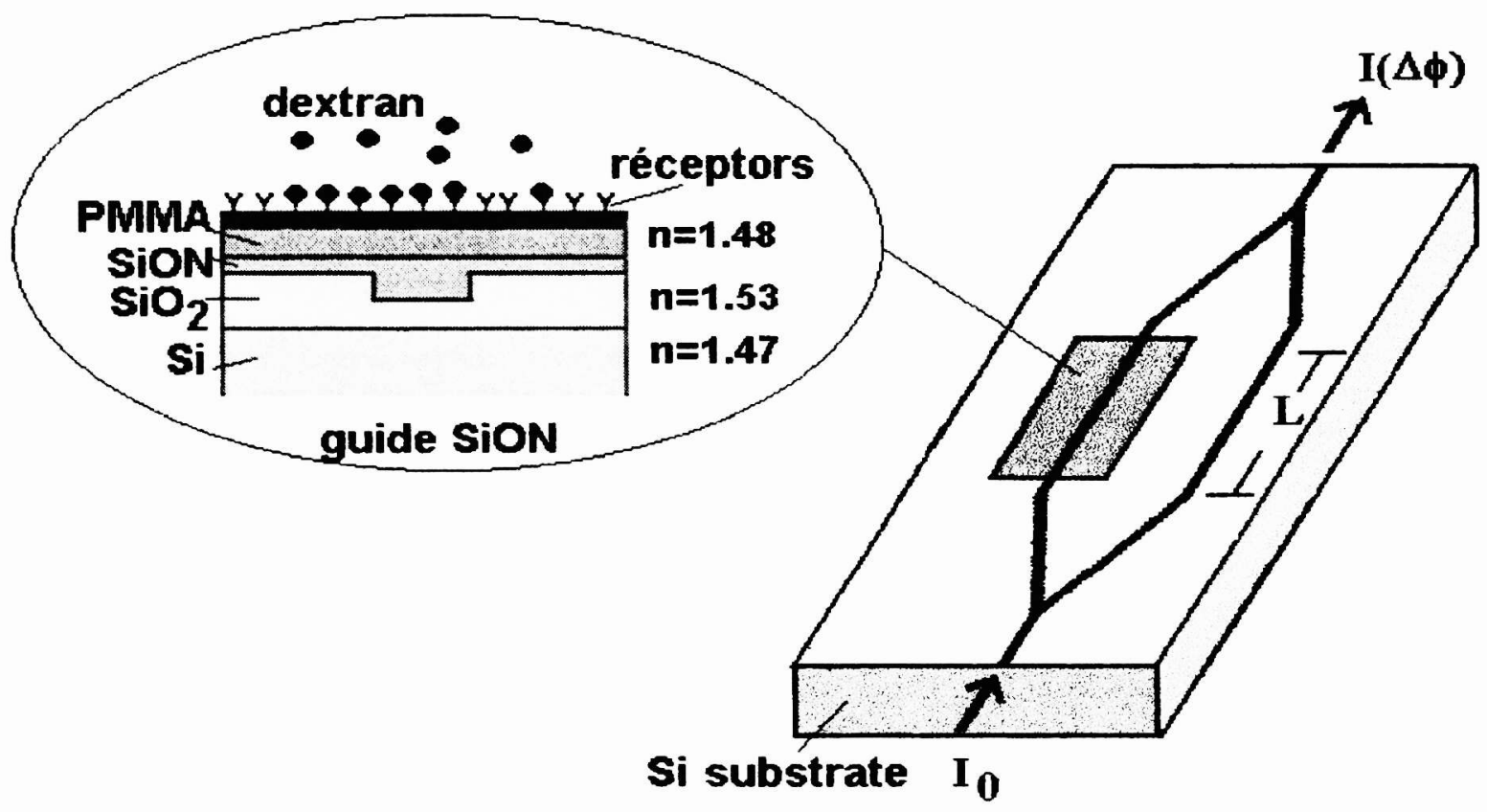

Figure 7 : Microinterferometer (reactive ion etching (RIE) of the $\mathrm{SiO}_{2}$ upper layer on Si substrate (Gorecki et al. 97)) for in situ measurement of capillaro-alveolar permeability via the measurement of a marker 


\section{Model driven acquisition}

Finally we can say that medical optronics is an important step in an entire chain of acquisition and processing of medical data, capable to create the medical knowledge a surgeon or a physician needs for diagnosis or therapy purposes. Optimizing the teaching of medical optronics needs a complete integration from acquiring to modelling the medical reality. This tendancy to give a holistic education in medical imaging and instrumentation is called "Model driven Acquisition" learning. The acquisition process is not isolated, but takes part of a whole programme of observing and modelling the medical reality, serving for example as a template for generating an augmented reality a physician and a surgeon can exploit in order to improve their classical diagnostic or therapic procedures. This augmented reality has to be communicated to the surgeon via an auditory, visual or lingual stimulus, forcing them to remain in the limits of a predefined region of surgical action (in which he is allowed to cut organs, to perform biopsy punctures or to pinch vessels). Anatomic and physiologic modelling have then to be used as a bayesian a priori knowledge (coming from anatomic images atlas or from physiologic reference data bases) in order to improve the acquisition, focussing on crucial observables optimizing the diagnosis or the therapy. We give below an extented bibliography on the intersection domain between acquisition and modelling.

\section{Conclusion}

New jobs are now occurring in medical or in surgical practice : a specific corresponding teaching has to be introduced both in faculties of medicine and in engineering institutes, in order to offer to medical people or to engineers the possibility to cooperate in order to improve the patient care. Teaching optronics at a high level (master or $\mathrm{PhD}$ degree) is an essential component of a new multi-disciplinary education based on an excellent knowledge of the acquisition procedures joined to a real ability to model the bio-medical reality : the future of many necessary new medical fields, like telemedicine, computer aided surgery and ambulatory functional exploration is entirely dependent on the capacity we have to create new adapted inter-disciplinary curriculae, especially in optics and electronics.

\section{References}

Bainville, E. (1995). \{3D reconstruction using a new dynamic model : the $\delta$-snakes $\}$. Grenoble, Research Report TIMC-IMAG Université J. Fourier.

Benabid, A.L., Cinquin, P., Lavallée, S., Le Bas, J.F., Demongeot, J. and de Rougemont, J. (1987). A computer driven robot for stereotactic surgery connected to cat-scan magnetic resonance imaging. Technological design and preliminary results, \{Applied Neurophysiology\} \{50\}, 153-154.

Benabid, A.L., Lavallée, S., Hoffmann, D., Cinquin, P., Demongeot, J. and Danel, V.F. (1992). Potential use of robots in endoscopic neurosurgery, \{Acta Neurochir. $\}$ \{54\}, 93-97.

Bernard GR et al. The American-European Consensus Conference on ARDS. Am. Rev. Respir. Dis., 1994; $149: 818-824$.

Berthommier, F., Francois, O., Coll, T., Hervé, T., Marque, I., Cinquin, P. and Demongeot, J. (1991). Asymptotic behavior of neural networks and image processing. In : A. Babloyantz, ed., \{Self-Organization, Emerging properties and Learning \} : 219-230. New York, NATO Series, Plenum Press.

Berthommier, F., Bouchard, V., Brunie, L., Colombet, L., Cinquin, P., Demongeot, J., Desbat, L., Dessenne, V., Lavallée, S., Martiel, J.L., Nérot, O., Prilly, L., Promayon, E., Rouault, S. and Troccaz, J. (1993). Medical imaging and modelling using a MasPar, \{Proceedings PARCO 93\}.

Bettega, G. (1992). \{A la recherche de la 4ème dimension $\}$. Grenoble, $\mathrm{PhD}$ Thesis Université J. Fourier.

Blankenship, T. (1987). Real-time enhancement of medical ultrasound images. In : , L.W. Kessler, ed., \{Acoustical Imaging : 187-195. Plenum, New York.

Breen, E.J. and Williams, K.L. (1994). Optical flow analysis of the ventral cellular layer of the migrating Dictyostelium dicoideum slug, \{Microbiology $\{140\}, 1241-1253$.

Bronk, K. S., Michael, K. L., Combined imaging and chemical sensing using a single optical imaging fiber. Analytical Chemistry. Vol 67. N¹7. 2750-2757. September 1. 1995.

Brunie, L., Lavallée, S., Troccaz, J., Cinquin, P. and Bolla, M. (1993). Pre- and intra-radiotherapy multimodal image registration, $\{\mathrm{J}$. Radiotherapy and Oncology $\}$ \{29\}, 244-252.

Brunie, L., Leitner, F., Berthommier, F., Cinquin, P. and Demongeot, J. (1995). Interpretation of multimodal medical images using connectionist and variational methods, \{Technology and Health Care $\}$ \{3\}, 91-100.

Bulthoff, H., Poggio, T. and Little, J. (1989). A parallel algorithm for real-time computation of optical flow, \{Nature $\{337\}, 549-554$. 
Catté, F., Lions, P.L., Morel, J.M. and Coll, T. (1992). Image selective smoothing and edge detection by nonlinear diffusion, \{SIAM J. Numer. Anal. $\{29\}, 182-193$.

Chen, Y. and Medioni, G. (1995). Description of complex objects from multiple range images using inflating balloon model, \{Computer Vision \& Image Understanding $\}$ \{61\}, 325-334.

Chou, W.S. and Chen, Y.C. (1993). Estimation of the velocity field of 2-d deformable motion, \{Pattern Recognition $\}\{26\}, 351-364$.

Cinquin, P., Demongeot, J., Troccaz, J., Lavallée, S., Champleboux, G., Brunie, L., Leitner, F., Sautot, P., Mazier, B., Perez, A., Djaid, M., Fortin, T., Chenin, M. and Chapel, A. (1992). Igor : image guided operating robot. Methodology, medical applications, results, $\{$ ITBM $\}\{13\}, 373-393$.

Cohen, L.D. (1991). On active contour models and balloons, \{Computer Vision \& Image Understanding\} $\{53\}, 211-218$.

Collins, J.J. and Richmond, S.A. (1994). Hard-wired central pattern generators for quadrupedal locomotion, \{Biol. Cybern. $\{$ \{11\}, 375-385.

Cosnard, M. and Demongeot, J. (1985). Attracteurs : une approche déterministe, \{C.R. Acad. Sc.\} $\{300\}, 551-556$.

Cottet, G.H. (1991). Modèles de réaction-diffusion pour des réseaux de neurones stochastiques et déterministes, \{C.R.Acad.Sc. $\{312\}, 217-221$.

Cottet, G.H. and Germain, L. (1993). Image processing through reaction combined with non-linear diffusion, \{Mathematics of Computation $\}\{61\}, 659-673$.

Cottet, G.H. (to appear). Neural networks : continuous approach and applications to image processing, \{J. Biol. Systems

De Rio, L.B., Gomez, A. and Yacaman,M.J. (1991). Image processing in TEM using the wavelet transform, \{Ultramicroscopy $\{38\}, 319-324$.

Demongeot, J. and Jacob, C. (1989). Confineurs : une approche stochastique, \{C.R. Acad. Sc.\} \{56\}, 206210.

Demongeot, J. (1995). Chirurgie assistée par ordinateur : bilan et perspectives, \{Chirurgie\} \{120\},300-307. Doyen, L. (1995). Mutational equations for shapes and vision-based control, \{J. Math. Imaging \& Vision $\{5\}, 99-109$.

Duncan, J.H. and Chou, T.C. (1992). On the detection of motion and the computation of optical flow, \{IEEE Trans. Pattern Anal. \& Machine Intell. $\}\{14\}, 346-353$.

Elomary, Y., (1994). \{Modèles déformables et multi-résolution pour la détection des contours en traitement d'images $\}$. Grenoble, $\mathrm{PhD}$ Thesis, Université J. Fourier.

Fay, D.A. and Waxman, A.M. (1991). Real-time early vision neurocomputing, \{IEEE International Joint Conference on Neural Networks $\}$ \{1\}, 621-626.

Francois, O., Demongeot, J. and Hervé, T. (1992). Convergence of self-organizing stochastic neural network processes, \{Neural Networks\} \{5\}, 277-282.

Fischer, J.R. and Dorband, J. (1991). Applications of the MasPar MP-1 at NASA/Goddard, \{IEEE Compcon 91\}, 278-282.

Goldie RG et al. Mechanisms of increased airway microvascular permeability: role in airway inflammation and obstruction. Clin Exp Pharmacol Physiol 1995 Jun-Jul;22(6-7):387-96

Gorecki, G., Chollet, F., Silicon-based integrated interferometer with phase modulation driven by surface acoustic wave. Optics Letters. Vol 22. N²3. December 1997.

Gorecki, G., Hervé, T., Bonotte, E., Grimbert, F., Bayat, S., Kawakatsu, H., capteur optique sur substrat silicium et application à la mesure in situ d'un marqueur fluorescent dans les petites bronches. French patent ; $N^{\circ} 9801877.1998$.

Gorecki, G., Hervé, T., Bonotte, E., Grimbert, F., Bayat, S., Kawakatsu, H., Microinterferometer on silicon substrate for measuring capillaro-alveolar permeability, US Patent $N^{\circ}$ 09/023. 1998

Haibo, L., Roivainen, P. and Forchheimer, R. (1993). 3-d motion estimation in model-based facial image coding, IEEE Trans. Pattern Anal. \& Machine Intell. $\}$ \{15\}, 545-556.

Healey, B. G., Walt, D. R., Fast temporal response fiber-optic chemical sensors based on the photodeposition of micrometer-scale polymer arrays. Anlytical Chemistry. Vol 69. N¹1. 2213-2216. June 1. 1997.

Heidman, R. G., Veldhuis, G.J., Fabrication and packaging of integrated chemo-optical sensors. Sensors and Actuators B 35-36. 234-240. 1996.

Heitz , F. and Bouthemy, P. (1993). Multimodal estimation of discontinuous optical flow using Markov random fields, \{IEEE Trans. Pattern Anal. \& Machine Intell. $\}$ 15\}, 1217-1233.

Hervé, T., Bagnaninchi, P., Gorecki, C., Bayat, S., Grimbert, F., Mesure de la perméabilité bronchoalvéolaire par microinterférométrie, journées microsystème du CNRS, Paris, novembre 1998.

Hervé, T., and Demongeot, J., (1988). Random field and tonotopy : simulation of an auditory neural network, $\{$ Neural Networks $\}\{1, \mathrm{~S} 1\}, 297$. 
Hervé, T., Dolmazon, J.M., and Demongeot, J., (1990). Random field and neural information : a new representation for multi-neuronal activity, \{Proc. Natl. Acad. Sc. $\}$ \{87\}, 806-810.

Hulsmann Ar et al. Am J Respir Crit Care Med 1996 Feb;153(2):841-6

Jian, L., Healy Jr., D.M. and Weaver, J.B. (1994). Contrast enhancement of medical images using multiscale edge representation, \{Optical Engineering\} \{33\}, 2151-2161.

Jorens, P.G., et al. Interleukin 8 (IL-8) in the bronchoalveolar lavage fluid from patients with the adult respiratory distress syndrome (ARDS) and patients at risk for ARDS. Cytokine 1992; 4: 592-597

Kass, M., Witkin, M.A. and Terzopoulos, D. (1987). Snakes : active contour models, \{Int. J. Comp. Vision\} $\{1\}, 321-331$.

Khellaf, A., Beghdadi, A. and Dupoisot, H. (1991). Entropic contrast enhancement, \{IEE Trans. Med. Im.\} $\{10\}, 589-592$.

Kichenassamy, S., Kumar, A., Olver, P., Tannenbaum, A. and Yezzi, J.R. (1995). Gradient flows and geometric active contour models, $\{\mathrm{ICCV}\}$.

Kobayashi, H., Matsumoto, T., Yagi, T. and Shimmi, T. (1991). A layered architecture for regularization vision chips, \{IEEE International Joint Conference on Neural Networks\} \{2\}, 1007-1020.

Kobayashi, H., Matsumoto, T., Yagi, T. and Shimmi, T. (1993). Image processing regularization filters on layered architecture, \{Neural Networks $\}\{6\}, 327-350$.

Kobayashi, N., Saito, H. and Nakajima, M. (1994). Fast adaptive contrast enhancement method for the display of gray-tone images, $\{$ Trans. IEICE $\}$ \{77\}, 502-509.

Kwon, T.M. and Zervakis, M.E. (1992). Design of regularization filters with linear neural networks (image restoration), \{IEEE Conf. on Systems, Man \& Cybernetics $\}\{1\}, 416-421$.

Leitner, F., Marque, I., Berthommier, F., Coll, T., François, O., Cinquin, P. and Demongeot, J. (1991). Neural networks, differential systems and image processing. In : J.C. Simon, ed., \{ From Pixels to Features II $\}: 253-$ 274. Amsterdam, North Holland.

Leitner, F., Paillasson, P., Ronot, X. and Demongeot, J. (1995). Dynamical functional and structural analysis of living cells : new tools for vital staining of nuclear DNA and for characterization of cell migration, \{Acta Biotheoretica\}.

Le Negrate, A., Beghdadi, A. and Dupoisot, H. (1992). An image enhancement technique and its evaluation through bimodality analysis, \{CGVIP: Graphical Models and Image Processing $\}$ \{54\}, 13-22.

Luettgen, M.R., Karl, W.C. and Willsky, A.S. (1994). Efficient multi-scale regularization with applications to the computation of optical flow, \{IEEE Trans. Image Processing $\}\{3\}, 41-65$.

Mailloux, G.E., Langlois, F., Simard, P.Y. and Bertrand, M. (1989). Restoration of the velocity field of the heart from $2 D$ echocardiograms, \{IEEE Trans. Med. Imaging $\}$ \{8\}, 143-153.

Martin, J. P. (1988). Fast enhancement technique for PC-based image processing systems, \{Diagnostic Imaging Magazine $\}$ \{1\}, 194-198.

Masson, G and Pailhous, J. (1994). Modulations of the optical flow did not induce locomotor pattern fluctuations in treadmill walking in man, \{Perceptual \& Motor Skills\} \{78\}, 755-763.

Matthay, M.A., et al. Salt and water transport across alveolar and distal airway epithelia in the adult lung. Am J Physiol (1996 Apr) 270(4 Pt 1):L487-503

Mattes, J., Trystram, D. and Demongeot, J. (1999). Parallel image processing : application to gradient enhancement of medical images, $\{$ Parallel Proc. Letters $\}\{8\}, 205-214$.

Meunier, J., Bertrand, M., Mailloux , G.E. and Petitclerc, R. (1988). Assessing local myocardial deformation from speckle tracking in echography, \{SPIE\} \{914\}, 20-29.

Montanvert, A., Meer, P. and Rosenfeld, A. (1991). Hierarchical image analysis using irregular tesselations, \{IEEE Trans. Pattern Anal. \& Machine Intell.) \{13\}, 307-316.

Nabet, B., Darling, R.B. and Pinter, R.B. (1992). Implementation of front-end processor neural networks, $\{$ Neural Networks $\}$ \{5\}, 891-902.

Nakahira, H., Maruyama, M., Ueda , H. and Yamada, H. (1993). An image processing system using image signal multiprocessors (ISMPs), \{Journal of VLSI Signal Processing\} \{5\}, 133-140.

Narayanaswamy, R., Current developments in optical biochemical sensors. Biosensors and Bioelectronics 6 (1991) 467 - 475.

Neycenssac, F. (1993). Contrast enhancement using the Laplacian of a Gaussian filter, \{CVGIP : Graphical Models and Image Processing $\}$ \{55\}, 447-463.

Ning, F. and Ming, C. (1993). An automatic cross-over point selection technique for image enhancement using fuzzy sets, \{Pattern Rec. Letters $\}$ \{14\}, 397-406.

Outrata, J. V. (1990). On generalized gradients in optimization problems with set-valued constraints, \{Mathematics of Op. Research\} \{15\}, 626-639.

Peitgen, H.O., Jürgens, H. and Saupe, D. (1992). \{Chaos and fractals $\}$. New York, Springer Verlag. 
Radcliffe, T., Rajapakshe, R. and Shalev, S. (1994). Pseudocorrelation : a fast, robust, absolute, grey-level image alignment algorithm, \{Medical Physics\} \{21\}, 761-769.

Roberts, L. (1994). Leroy Hood : thinking big in Seattle, \{Science\} \{264\}, 206-209.

Shah, M., Rangarajan, K. and Tsai, P.S. (1993). Motion trajectories, \{IEEE Trans. Systems, Man \& Cybern.\} $\{23\}, 1138-1151$.

Robinson., R., A rapid one step assay for prostate specific antigen in whole blood using an optical immunoassay technology. Medical sensors II and Fiber optics sensors. SPIE Vol 2331. 26-31. 1994.

Sherratt, J.A. and Murray, J.D. (1992). Epidermal wound healing : the clinical implications of a simple mathematical model , \{Cell Transplantation\} \{1\},365-371.

Shi, B.E., Roska, T. and Chua, L.O. (1993). Design of linear cellular neural networks for motion sensitive filtering, $\{$ IEEE Trans. Circuits \& Systems II $\}\{40\}$ 320-332.

Silverman, J. (1993). Local contrast enhancement of IR images, \{SPIE,\} \{2075\}, 169-184.

Steinberg, K.,P., et al.Safety of bronchoalveolar lavage in patients with adult respiratory distress syndrome. Am Rev Respir Dis 1993; 148: 556-561Toet, A. (1992). Multiscale contrast enhancement with applications to image fusion, \{Optical Engineering $\}$ \{31\}, 1026-1031.

Toborg, S.T. and Huang, K. (1991). Cooperative vision integration through data-parallel neural computations, \{IEEE Trans. on Computers $\}$ \{40\}, 1368-1380.

Tracqui, P., Cruywagen, G.C.,. Woodward, D.E, Bartoo, G.T., Murray, J.D. and Alvord Jr., E.C. (1995). A mathematical model of glioma growth : the effect of chemotherapy on spatio-temporal growth, \{Cell Proliferation $\}$ \{28\}, 17-31.

Vinod, V.V., Chaudhury, S., Mukherjee, J. and Ghose, S. (1994). A connectionist approach for clustering with applications in image analysis, \{IEEE Trans. on Systems, Man and Cybernetics $\}$ \{24\} 365-385.

Walt, D. R. , Agayn, V., Fluorescent optical sensors. Applied Biochemistry and Biotechnology. Vol. 41. 129138. 1993.

Waxman, A.M., Seibert, M., Cunningham, R. and Jian, W. (1988). The neural analog diffusion enhancement layer (NADEL) and early visual processing, \{SPIE $\}$ \{1001\}, 1093-1102.

Willersinn, D., Bertin E. and Kropatsch W. (1994). \{Dual irregular Voronoï pyramids and segmentation\}. Wien, Technical report PRIP-TR-27\} Technical University.

Wolfbeis., O.S., Fiber optical fluorosensor for determination of halothane and/or oxygen. Anal. Chem. 57, 2556-2561. 1985.

Zappe, H. P., Amot, H. E., Technology and devices for hybrid and monolithically integrated optical sensors. Sensors and Actuators A. 41-43. 141-144. 1994. 